\title{
The Creative Abilities' Development as the Component of the Process of Formation Soft Skills with the Help of Distant Technologies
}

\author{
Hanna Alieksieieva, Nataliia Kravchenko, Larysa Horbatiuk, Viktoriia Zhyhir, Olena Chernieha \\ Faculty of Physical, Mathematical, Computer and Technological Education, Berdiansk State Pedagogical University, \\ Berdiansk, Ukraine \\ Email: alekseeva@ukr.net
}

How to cite this paper: Alieksieieva, $\mathrm{H}$., Kravchenko, N., Horbatiuk, L., Zhyhir, V., \& Chernieha, O. (2020). The Creative Abilities' Development as the Component of the Process of Formation Soft Skills with the Help of Distant Technologies. Creative Education, 11, 2499-2511.

https://doi.org/10.4236/ce.2020.1112183

Received: October 19, 2020

Accepted: December 6, 2020

Published: December 9, 2020

Copyright $\odot 2020$ by author(s) and Scientific Research Publishing Inc. This work is licensed under the Creative Commons Attribution International License (CC BY 4.0).

http://creativecommons.org/licenses/by/4.0/ (c) (i) Open Access

\begin{abstract}
The article is dedicated to the problem of the development of the creative abilities of students as the component of soft skills. The conditions for the formation of the creative professional potential of future professionals are considered. There is determined that the necessary condition for the formation of the creative professional potential of the future specialists is the motivation on the student's creative self-actualization. During the process of the formation of the creative professional potential of future specialists, the leading role is given to the informational cognitive program and subject-genesis of the professional reflection. It is proposed the model of formation of the creative professional potential of future specialists. To describe the conceptual model, the methodology of functional modeling within the graphical notation IDEF0 is used. There is determined that for the formation of the creative abilities during distant learning it is advisable to use systems of education's management, to use cloud-technologies, systems of videoconferences' organization, messengers. There is described the experience of the formation of the creative professional potential of students of Berdiansk State Pedagogical University with the help of distance learning.
\end{abstract}

\section{Keywords}

Professional Education, Distance Learning, Creative Abilities, Soft Skills

\section{Introduction}

Training of the modern specialist provides the formation not only the professional competences, but also this provides the formation of professional and socially important features (Moravec \& Cobo, 2013). Modern state of the system of 
higher education requires the search of new ways of organization of the educational process which provides the formation of socially important features of the future teacher. Such features include the complex of non-specialized, extra-professional skills which are responsible for the successful participants in the process of work, for the high effectiveness and which are not connected with the certain sphere (Cobo, 2013). These skills are called "soft skills".

Such "soft" skills usually are called universal or functional competences and the fact of mastering theses skills is called the functional literacy. UNESCO and European commission even maintained the minimum level of such literacy, which is necessary for every European who wants to be a full member of the society (Dluhunovych, 2014). Ukrainian researchers note that mastering foreign language communicative competence is a necessary condition for Ukraine's integration into the world community (Horbatiuk, Alieksieieva, Kravchenko, Lipych, \& Rozumna, 2019). Recent research works of the labor market reflect the tendency of the significant interest of the employers in such skills which must be obtained by the employee. The majority of employers consider soft skills as important as the professional knowledge and skills. Eventually professional skills tend to become obsolete but soft skills are always actual. According to research works, which were conducted at Harvard university and Stanford university, only $15 \%$ of the carrier success are provided by the level of professional skills. And $85 \%$ are provided by the Soft Skills (Koliada \& Kravchenko, 2020). In Ukraine university pay the significant role to the development of "soft skills" taking into account the demands of the labor market (Shchetynina, Horbatiuk, Alieksieieva, \& Kravchenko, 2019).

The list of "soft skills" includes:

- ability to work in time: ability to listen, ability to see the common goal and to find the ways of its achieving, ability to combine own ambitions with the collective business, readiness to support, ability to persuade and to find the compromise;

- leadership qualities; ability to unite people around the socially important goal, ability to take the responsibility for the collective;

- organizational abilities: ability to unite people and to clearly determine duties according to the possibilities of everyone, initiative and strictness to others and to themselves;

- communication: skills to communicate according to the situation, to consider mimics and gestures, ability to make a deal, to start and to finish the conversation appropriately, to sum up the results of the conversation, readiness to communicate with client of different age;

- emotional intellect: ability to recognize emotions of other people and to demonstrate own emotions, to maintain the contact for the teamwork;

- work with the information: skills to collect, to analyze and to evaluate new information, to ask needed questions and to orient within the wide informational field of the modern world;

- systematic thinking: skills to plan, to state current and final goals and to real- 
ize these goals, to analyze the complex situations, to find the optimal solution;

- motivation: skills to motivate themselves and their clients, to understand motives and intentions of other people, to overcome problems and crisis, to motivate clients to do this;

- creativity: ability to find non-standard, new solutions of the familiar situations, ability to generate new ideas and to bring them to life (Robles, 2012).

The significant attention should be given to the development of the creativity which, according to scientists, is connected with the mental activity of the personality (Androshchuk, Balakhtar, Balakhtar, \& Oleshko, 2020). Scientists determine its crucial role and consider creativity as the important form of the human practice, activation of the subject's potential during the personal changes. T. Schmid determine value to the health of creativity. Creativity derives from biological changes during human evolution as a tool that is needed for survival. The successful use of creativity generates feelings of pleasure and self-esteem (Schmid, 2006).

\section{Methodological Proposal}

Formation of the creative personality of the future specialist, training this personality for the creativity is the problem which solution has not been found yet. The creative individuality of the specialist is the systematic, integral personal phenomena which comprises the set of intellectual, motivational, motional-willing and professional-value features (Thompson \& Lordan, 1999).

Personality's creative potential has complex and systematic character; it reveals at all levels of the individuality: at biological-physiological, at social and ant mental level. There are such leading factors of formation of subjective professional-creative position of the student: reflection, self-determination and selfactualization.

Process of education will develop the creativity considering such principles:

- awareness (it is achieved during the reflection of the process and result);

- management of subject activity (self-organization);

- self-expression-changes (with the aim of improvement) along with the further development during the process of the constant move from one state to another: from less effective to the more effective.

We consider that due to the reflexive position of the student it is formed the experience of the creative activity through the actualization of the creativity itself and the student transforms from the passive receiver into the active subject of cognition (Seryozhnikova, 2011).

The mechanism of formation of the creative potential of the future specialist contains in itself main stages of subject-genesis (Ohnev, 1997). The subject-genesis provides the "conscious transformation of the personality's experience due to the reflexive procedures (retrospective and perspective reflections". As the mechanism of the subject-genesis we consider the overcoming of the informational 
non-determination within each stage along with their consistency; self-sanctioning of each future action; responsible permission, which the personality gives himself (herself) for each future action. The successful passing of stages of the subject-genesis consistently enriches and widens the professional-creative opportunities of students at the next stage and allows student to accept himself as the subject of the professional reflection. This is able to provide the effectiveness of the process of creative self-actualization of the future specialist. Gradually and consistently he will transform into the subject of own professional self-influence, self-education, self-development and self-actualization.

Drawing on the conceptual model of formation of the creative pedagogical potential which was developed by R. K. Serozhnikova (Serozhnikova, 2009), we have proposed the model of the formation of the creative professional potential of the future specialists.

For the description of the conceptual model we have used the methodology of the functional modeling within the graphical notation IDEF0, which is dedicated for the formalosation of the processes and for the description of processes.

Within the diagram of the formation of the creative professional potential of the future specialists (Figure 1) each of the four sides of the functional block has own certain value.

Management (arrow-pointer in the top of the block): Informational-cognitive educational program; Subject-genesis of the professional reflection.

Resources which perform the work (arrow-pointer underneath the block): Cooperative-creative activity of the teacher and student.

Incoming data:

- Motivation on creative self-actualization;

- Levels of formation of creative professional potential.

- Output data:

- Levels of formation of creative professional potential.

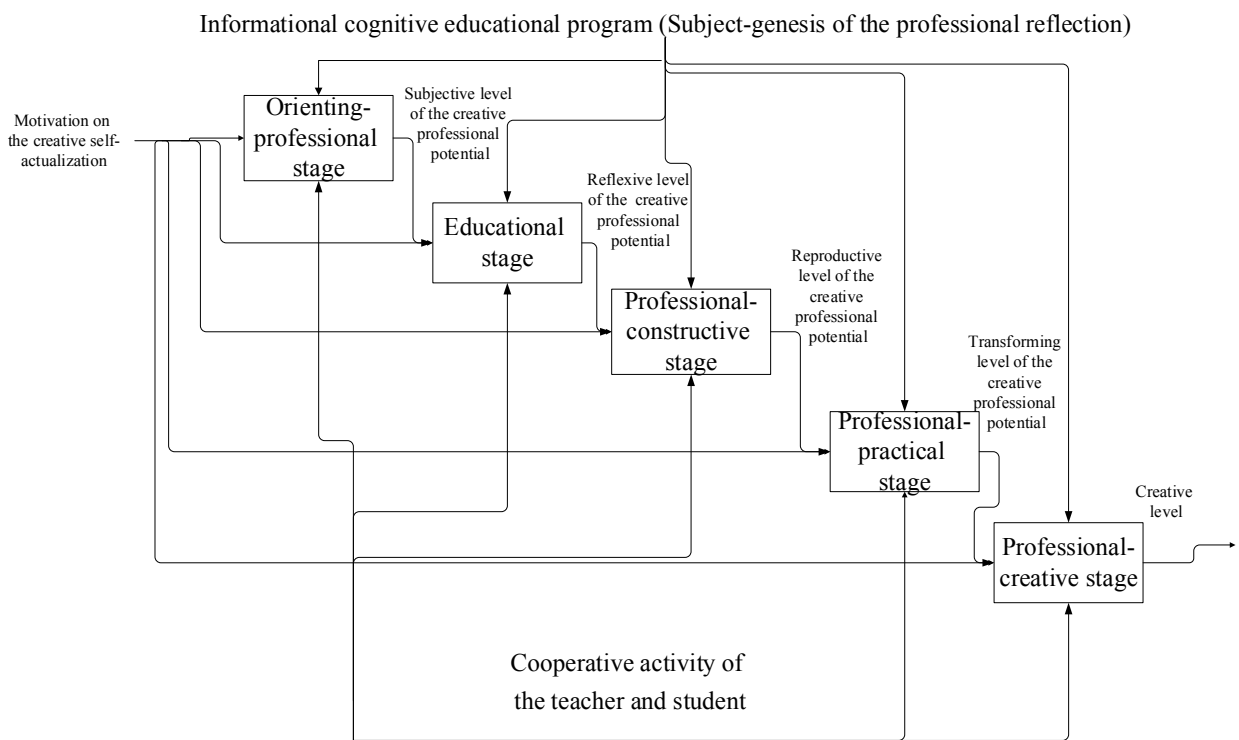

Figure 1. Formation of the creative professional potential of the future specialist. 
"Formation of the future specialists' creative professional potential" is detailed with the help of several blocks, which are connected with the help of interface arcs. The diagram consists of five blocks, which represent five stages of formation of creative professional potential of future specialists: indicative-professional stage, educational stage, professional-constructive stage, professional-practical stage, professional-creative stage (Heckman \& Kautz, 2012).

The necessary condition for the formation of the creative professional potential of the future specialists is the motivation on the student's creative self-actualization. During the process of the formation of creative professional potential of the future specialists the leading role is given to the informational cognitive program and subject-genesis of the professional reflection.

Each stage takes place within the tight interconnection of the student and teacher who is the integral driving mechanism and the main resource of this process. The goal of each stage is the formation of level of the creative professional potential. Each stage has the necessary condition. This condition is the motivation of the student's creative self-actualization and achievement of the previous level of the formation of the creative professional potential. Each stage passes through three levels of creativity (reproductive, heuristic and creative).

We can state such necessary and sufficient psychological-pedagogical conditions of the effective formation of the creative professional potential:

- Creation of the personally-oriented developing environment;

- Orientation of the professional-pedagogical process on the content of the personal-value training and mastering this phenomena;

- Phased character of the pedagogical forming impacts, their sequence and continuity;

- Optimality of the organizational-methodical ways which are oriented on the development of the future teacher.

Formation of the creative professional potential is the system which is oriented on the development of the creative personality which appears during the process of creativity due to the student's efforts, his or her creative activity, whose source is the student himself (herself) and professional tasks which are realized with the help of performing independent and individual works ("10000 videos Soft Skills", n.d.).

The construction of the conceptual model of formation of the creative professional potential of the future specialists helps to understand better the process of formation of the creative potential and allows to construct the methodic of formation of creative professional potential of the future specialists with the help of distance technologies.

Within modern conditions of the society's development the distance learning has become the global phenomena of the social culture, in particular, educational and informational culture. However the distance form of education has not been used yet for the development of the creativity of the applicants for higher education. 


\section{Research Results}

Modern-days conditions which are connected with the implementation of the quarantine's means (according to the spreading of the coronavirus disease (COVID-19) within majority of countries and on the territory of Ukraine) significantly complicate the organization of the effective teaching of the applicants for higher education. The implementation of the quarantine on the territory of Ukraine and some other measures of the prevention of the spreading of the coronavirus disease (COVID-19) makes the scientific and pedagogical community to look for the appropriate opportunities which will help to provide the development of the creativity of the future specialists, creation of pedagogical conditions for the revealing of the students' potential. One of such measures which have unique opportunities, is the distance learning.

We can visually represent the hierarchy of the systems of distance learning as the pyramide which is given in the Figure 2.

At the base of the pyramid there the means of course development. These systems provide the opportunity of developing distance educational materials on the basis of the visual programming or text editors.

At the second level there systems of management courses, which allow to create catalogues of graphical, audio, video- and text files. Such system is specialized data base which is provided with the mechanisms of research by keyword (metadata), aggregation of the educational (learning) content, document management. At the third level there systems of the learning management which allow to manage the educational process-users' register and their access rights, assigning of courses to the users, collecting and saving data and information about the users' actions (statistics of education, visits, usage of resources). On the top level of the pyramid there are systems of learning management and content management which combine within themselves the system of education management and system of management of educational content.

On the basis of the analysis of the existed systems of distance learning there were determined the most popular systems which are represented in the Table 1.

Practice of the formation of the creative professional potential of the future teachers at Ukrainian institutions of higher education, in particular at Berdiansk State Pedagogical University, proves the effectiveness of the programmed approach to the formation of the creative professional potential with the help of the distance learning.

For the formation of the creative professional potential of the future specialists it is necessary to implement the systematic approach of the modernization of the informational-communicative environment, integration of the informational-communicative technologies and psychological-pedagogical conditions within the educational process. The integration of the psychological-pedagogical conditions and informational-communicative environment allows to realize the programmed approach to the formation of the creative professional potential of the future specialists. 


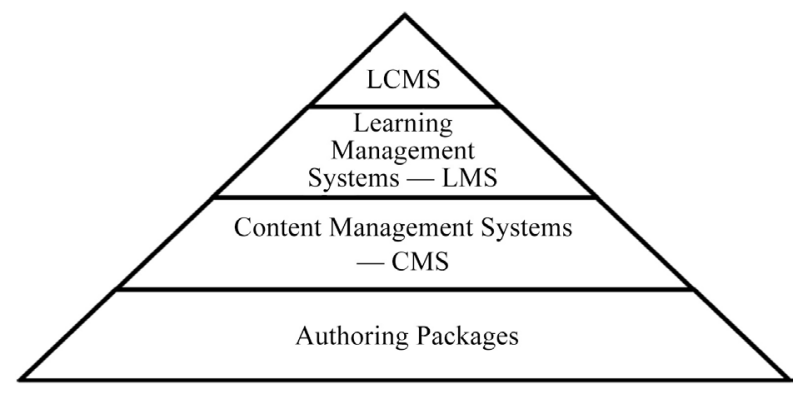

Figure 2. Hierarchy of distance learning systems.

Table 1. Systems of distance learning.

\begin{tabular}{|c|c|}
\hline $\begin{array}{l}\text { Means of organization } \\
\text { of distance learning }\end{array}$ & Example \\
\hline $\begin{array}{l}\text { Learning Content } \\
\text { Management } \\
\text { Systems-LCMS }\end{array}$ & $\begin{array}{l}\text { Moodle, Tovuti, Bridge, CoreAchieve, Coassemble, Absorb LMS, } \\
\text { SkyPrep, Intertek Alchemy, iSpring, WebTutor, Teachbase, GetCourse }\end{array}$ \\
\hline $\begin{array}{l}\text { Learning Management } \\
\text { Systems-LMS }\end{array}$ & ATutor, Claroline LMS, Dokeos, OLAT, Google Classroom \\
\hline $\begin{array}{l}\text { Content Management } \\
\text { Systems }\end{array}$ & $\begin{array}{l}\text { WordPress, Drupal, Joomla, Squarespace, Wix, Adobe Experience } \\
\text { Manager Sites, Magento }\end{array}$ \\
\hline Authoring Packages & $\begin{array}{l}\text { Video Editing Tools, Webcam And Teleconferencing Features, Screen } \\
\text { Capture Functionality, Rapid eLearning Authoring Capacity, Quiz } \\
\text { Creation, Real-World Activity Builders }\end{array}$ \\
\hline
\end{tabular}

Within the implementation of the programmed approach to the formation of the creative professional potential of the future specialists during the process of the professional training there were used way which are given in the Table 2.

Google Classroom and Moodle allow to create the personally-oriented, developing educational environment.

We have created tasks for the individual and independent work. These tasks are oriented on development of the students' professionally important qualities on each topic of the discipline. For the realization of the phased character of the pedagogical forming impacts it is necessary to include testing into the independent work. This will permit to determine the student's stage of the formation of creative professional potential. The input testing will also allow to conduct the research and monitoring of the effectiveness of the implementation of the pedagogical technologies.

For the determination of the level of the formation of creative professional potential we have used tests which were developed according to methods, developed by:

- T.D. Dubovitska for the determination of the students' level of the professional orientation;

- O.S. Anisimova for the determination of the level of reflection;

- S.M. Tarasova for the evaluation of the level of abilities for the self-development and self-education;

- P. Torrance for the evaluation of levels of creativity. 
Table 2. Means of implementation of the programmed approach to the formation of the creative professional potential.

\begin{tabular}{|c|c|}
\hline Name & Description \\
\hline Moodle & Learning management system \\
\hline Google Classroom & Web-service for the organization of learning \\
\hline WordPress & System of content management \\
\hline YouTube & Video-hosting which gives services on distribution video-materials \\
\hline Bandicam & Program for the recording video from the screen \\
\hline Camtasia Studio & Program for the recording video from the screen \\
\hline Movavi Screen & Program for the recording video from the screen \\
\hline Google search & The greatest search system of the internet. The main product of Google \\
\hline YouTube & The most popular video-hosting \\
\hline Gmail & E-mail \\
\hline Google Maps & Map-graphic system (mapping system) \\
\hline Google Drive & Cloud data storage \\
\hline Google Hangouts & Instant messaging (chat) video and voice communication \\
\hline Google Translate & Translation of words, texts, phrases, web-pages \\
\hline Google Docs & Text editor \\
\hline Google Sheets & Table editor \\
\hline Google Slides & Presentation editor \\
\hline Google Forms & Survey administration \\
\hline Blogger & Blogging-platform \\
\hline Google Calendar & $\begin{array}{l}\text { Online service for scheduling meetings, events and affairs considering the } \\
\text { calendar (with a link to the calendar) }\end{array}$ \\
\hline Google Groups & Creation of the internet-communities \\
\hline Google Sites & $\begin{array}{l}\text { Creation and hosting of the internet-sites with many additional opportunities } \\
\text { (editing sites by the great amount of users on the basis of wiki-technology, } \\
\text { implementation of other services, etc) }\end{array}$ \\
\hline
\end{tabular}

- The independent work of the student is oriented on the solution of such tasks:

- Improvement of the abilities to take part in the dialogue, to lead the discussion, to form and to ground logically own position on the problematic issues of theory and practice;

- Development of creative abilities during the process of the mastering content of the discipline;

- Search of the appropriate variants of solutions of the given tasks;

- Revealing of problems and ways of their solution.

The students perform the tasks, independently work with the educational literature, additional resources and scientific publications on the discipline. The students perform the tasks with the help of the informational-communicative means (Figures 3-5). 


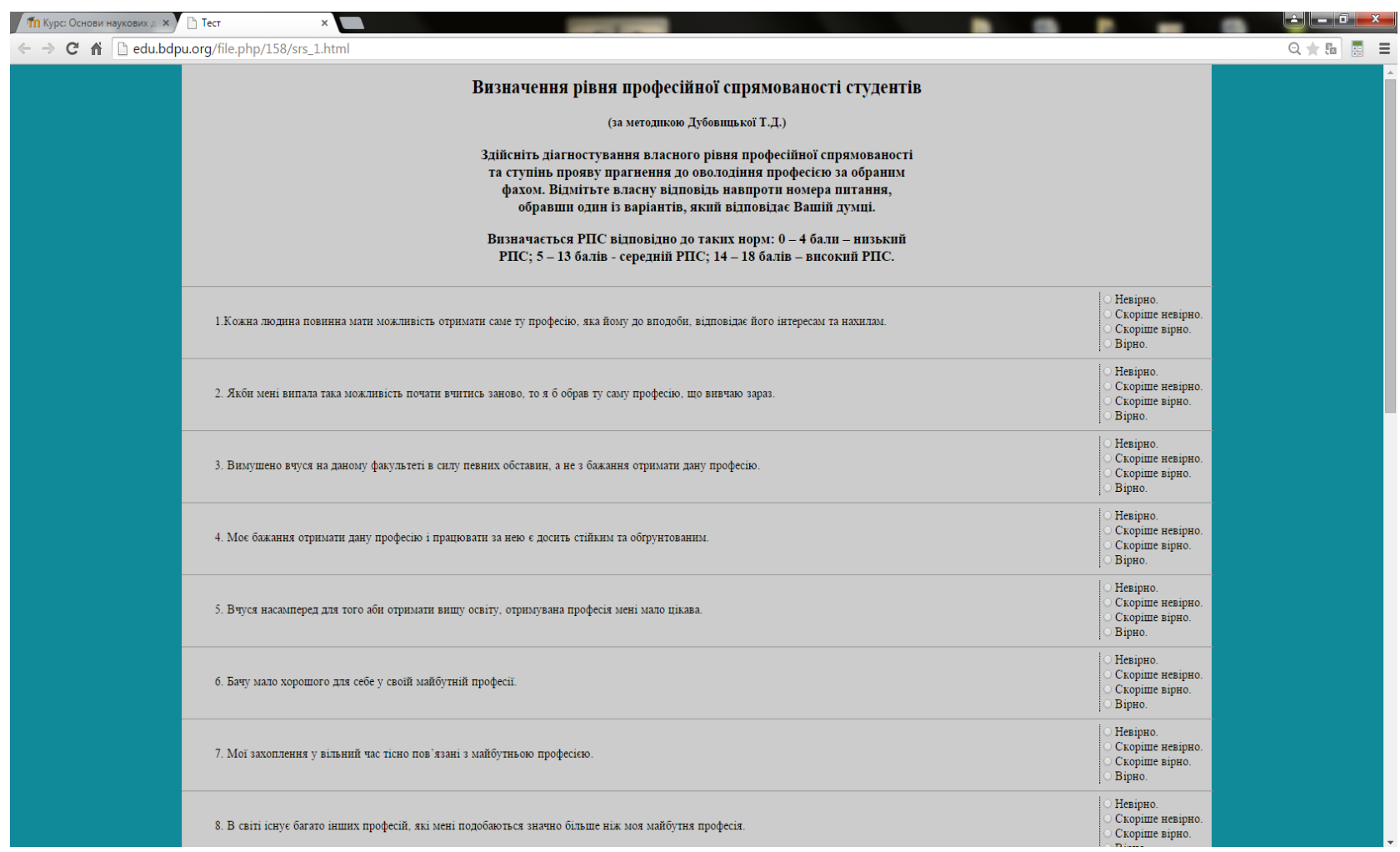

Figure 3. Testing according to the method of T.D. Dubovitska for the determination of the students' level of professional orientation.

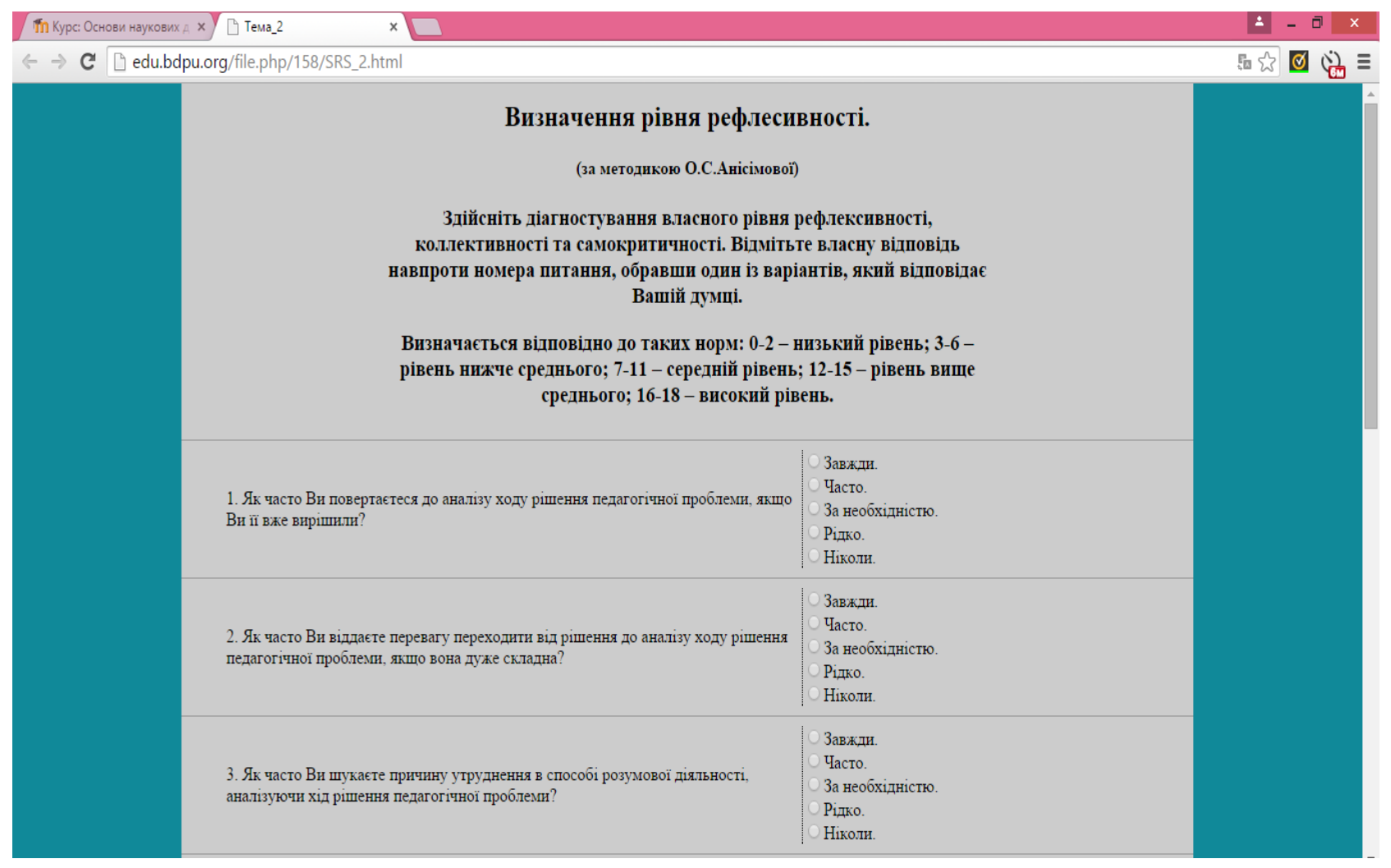

Figure 4. Testing according to the method of O.S.Anisimova. 


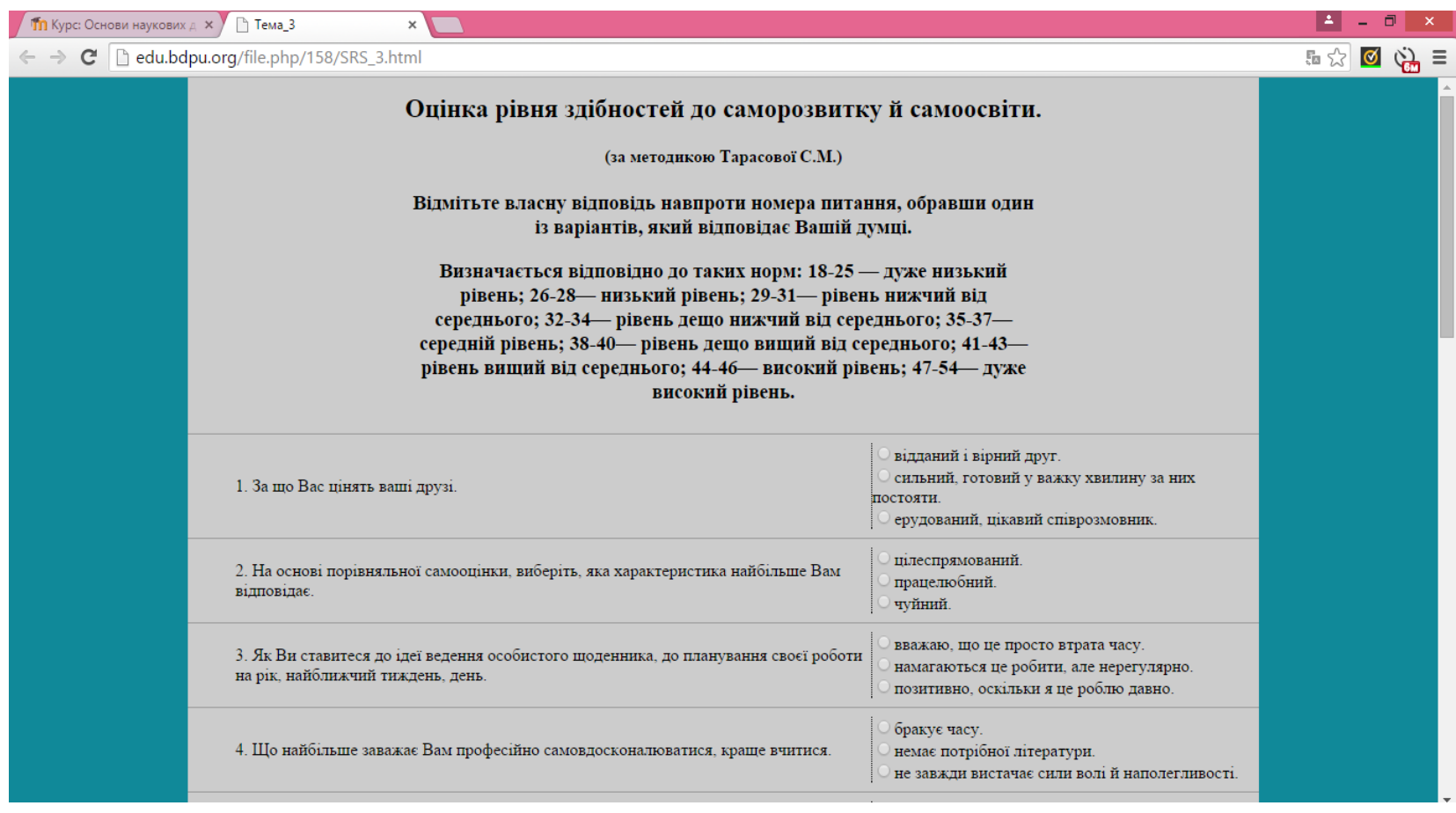

Figure 5. Testing according to the method of S.M.Tarasova for the evaluation of the level of abilities for the self-development and self-education.

Checking of the performed tasks during the seminars with the help of students' oral presentations and with the help of the collective discussion. For the development and improvement of the students' creative abilities there are organized theme discussions which are connected with the general problem of with the scientific work which is within the process of development.

The independent students' work includes the current and creative problemoriented independent work.

The creative independent work is oriented on the development of the intellectual skills, on the complex of universal competence, on the increasing of the students' creative potential.

This work includes:

- search, analysis, structuring and presentation of information;

- research work and participation in the students scientific conferences, seminars and Olympiads;

- projecting and performing of the own research;

- analysis of the scientific publications on the topic which was earlier determined by the teacher.

The individual tasks are necessary for the improvement knowledge on the discipline; for the development of the student's professional features, creative potential of the future specialist. The individual tasks allow students to master necessary practical skills during the solution of practical tasks; they provide the development of skills of the independent work and mastering methods of conducting scientific research works which are connected with the chosen topic.

For example, during the studying discipline "Fundamentals of the scientific 
research" the technology of development of students' creative professional potential contained the implementation of distance means of teaching along with the considering of the formation of the creative professional potential (Table 3).

Table 3. Means of implementation of the programmed approach to the formation of the creative professional potential.

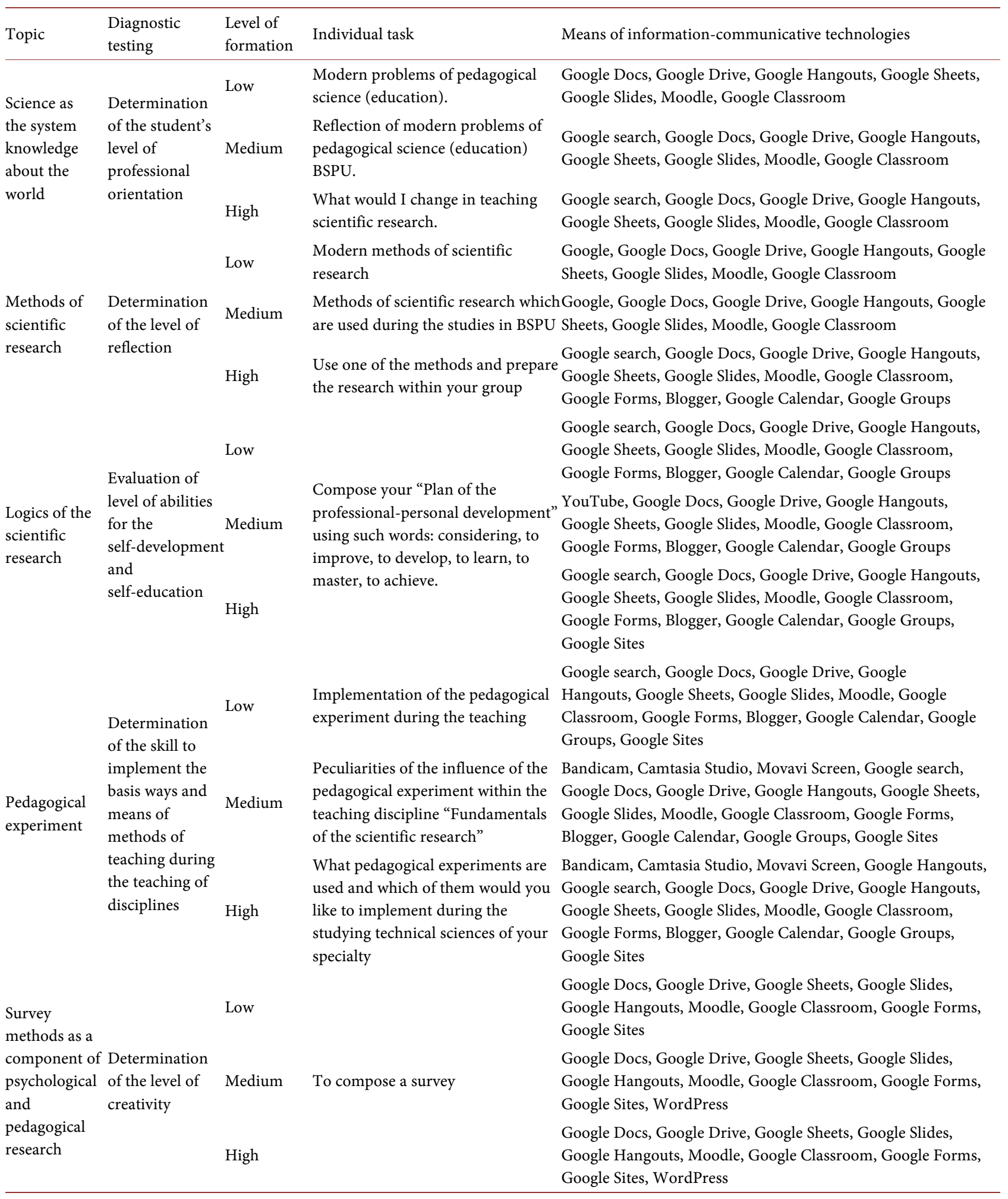


For example, during the performing of the first independent work it is necessary to determine the level of the student's professional orientation. This test allows to determine the overcoming of the orienting-professional stage by the student. Depending on the level of the professional orientation (high, medium, low) the individual task will be proposed to the student. The individual tasks are necessary for the improvement of the knowledge on discipline, for the development of the professional qualities and features, for the creative potential of the future specialist. The individual tasks allow student to master necessary practical skills during the solution of certain practical tasks which are connected with the topic which has been chosen.

\section{Conclusion}

During the process of the formation of creative professional potential of the future specialists the leading role is given to the informational cognitive program and subject-genesis of the professional reflection. Each stage takes place within the tight interconnection of the student and teacher who is the integral driving mechanism and the main resource of this process. The goal of each stage is the formation of level of the creative professional potential. Each stage has the necessary condition. This condition is the motivation of the student's creative selfactualization and achievement of the previous level of the formation of the creative professional potential. Each stage passes through three levels of creativity (reproductive, heuristic and creative).

It is proposed the model of formation of the creative professional potential of future specialists. To describe the conceptual model, the methodology of functional modeling within the graphical notation IDEF0 is used.

There is determined that for the formation of the creative abilities during distant learning it is advisable to use systems of education's management, to use cloud-technologies, systems of videoconferences' organization, messengers. There is described the experience of the formation of the creative professional potential of students of Berdiansk State Pedagogical University with the help of distance learning.

Thus the formation of the creative potential was considered as the technology of education which could be implemented during the professional training of the future specialist with the aim of providing of the effective mastering of the creative professional potential within the conditions of distance learning.

\section{Conflicts of Interest}

The authors declare no conflicts of interest regarding the publication of this paper.

\section{References}

(n.d.). 10000 Videos Soft Skills.

https://play.google.com/store/apps/details? id=com.thv.softskills\&hl=uk 
Androshchuk, I., Balakhtar, V., Balakhtar, K., \& Oleshko, P. (2020). Creativity as a Factor in the Psychological Well-Being of Teachers of Higher Educational Institutions. The New Educational Review, 60, 191-202.

Cobo, C. (2013). Skills for Innovation: Envisioning an Education That Prepares for the Changing World. Curriculum Journal, 24, 67-85.

https://doi.org/10.1080/09585176.2012.744330

Dluhunovych, N. A. (2014). Soft Skills as a Necessary Component of Training IT Professionals. Visnyk Khmelnytskoho natsionalnoho universytetu, 6, 239-242.

Heckman, J. J., \& Kautz, T. (2012). Hard Evidence on Soft Skills. Labour Economics, 19, 451-464. https://doi.org/10.1016/j.labeco.2012.05.014

Horbatiuk, L., Alieksieieva, H., Kravchenko, N., Lipych, V., \& Rozumna, T. (2019). Use of Mobile Applications for Foreign Language Lexical Competence Formation. Journal of History Culture and Art Research, 8, 113-124. https://doi.org/10.7596/taksad.v8i3.2093

Koliada, N., \& Kravchenko, O. (2020). Practical Experience of soft-Skills Formation in the Conditions of Higher Education Institution. Aktualni pytannia humanitarnykh nauk, 3, 137-145.

Moravec, J., \& Cobo, C. (2013). Mechanisms to Identify and Study the Demand for Innovation Skills in World-Renowned Organizations. On the Horizon, 21, 96-106. https://doi.org/10.1108/10748121311322996

Ohnev, A. S. (1997). Sub-Ectogenesis and Psychotraining of Self-Regulation.

Robles, M. M. (2012). Executive Perceptions of the Top 10 Soft Skills Needed in Today's Workplace. Business Communication Quarterly, 75, 453-465. https://doi.org/10.1177/1080569912460400

Schmid, T. (2006). Promoting Health through Creativity: For Professionals in Health, Arts and Education. Hoboken, NJ: John Wiley \& Sons.

Serozhnikova, R. K. (2009). The Future Teacher in the Space of Creative Development. Monograph. Donetsk. 335.

Seryozhnikova, R. K (2011). The Mechanism of Actualization of Creative Professional Potential of the Future Engineer.

Shchetynina, O., Horbatiuk, L., Alieksieieva, H., \& Kravchenko, N. (2019). Project Management Systems as Means of Development Students Time Management Skills. ICTERI, 370-384.

Thompson, G., \& Lordan, M. (1999). A Review of Creativity Principles Applied to Engineering Design. Proceedings of the Institution of Mechanical Engineers, Part E: Journal of Process Mechanical Engineering, 213, 17-31.

https://doi.org/10.1243/0954408991529960 